\title{
Information as form
}

\author{
Anis Pervez
}

Communication and Media Arts, American International University-Bangladesh, anispervez@gmail.com

\begin{abstract}
An interpretive and constructive understanding of information can be developed by drawing on a number of premises of autopoiesis in combination with Spencer-Brown's laws of form. Such understanding views information as selfreferential meaning construction by observing an object. Therefore, information can be perceived as form resulted from individuals' making distinction of their environment. By analyzing forms - token of indications - one can empirically understand what information is constructed. Such investigation is a qualitative exploration of human actions and interpretations.
\end{abstract}

Keywords: Autopoiesis, Self-reference, Laws of form, Observation, Indication

Acknowledgement: Debora Shaw

$\mathrm{T}$ he popularization of the term "information" has complicated its theoretical definitions because it is often difficult to put a rigid scientific boundary around a popular term. Information has been theorized from a number of perspectives across different disciplines; one can find several perspectives on information within information science. Some of the understandings are supplementary and complementary to each other. There are also understandings that are quite contradictory. For some, information has an objective status. A growing number of scholars, however, see information as an emergent property. This second perspective has a sound basis and appeals because it takes individuals as the focus; but methodological tools are inadequate to operationalize this qualitative and phenomenological approach to understanding information. The objective of this paper is to offer an interpretive understanding of information that can be empirically investigated. I argue that information is form taking caused by the way individuals self-referentially make distinctions to their environments. Some premises of autopoiesis in combination with Spencer-
Brown's laws of form facilitate such an understanding.

\section{Diversity of the conceptions of information}

Some researchers view information as data - mechanical, economic, or sensory - that can be understood as a commodity or physical resource (Artandi, 1973; Boulding, 1956; Budd \& Ruben, 1979; Horton, 1979; Lancaster \& Gillespie, 1970; Lipetz, 1970; Luftus \& Luftus, 1976; Rogers \& Kincaid, 1981; Ruben, 1972, 1984; Thayer, 1968; Williams, 1979). For some, it is a signal (Cherry, 1966; Watzlawick, Beavin, \& Jackson, 1967), code (Cannon \& Luecke, 1980; Maruyama; 1968, Masuda, 1981), symbol (Lin, 1973) or message (Fisher, 1979; MacKay, 1952a, 1952b; Rapoport, 1982; Shannon \& Weaver, 1949). According to McLuhan (1964) information is a medium. A significant number of scholars understands information as formal or recovered knowledge (Boorstein, 1961; Davidson, Boylan, \& Yu, 1976; Machlup, 1962; McCroskey, 1968) whereas Boulding (1956), Goffman (1974), Ruben (1984), and Whittmore and Yovitz (1973) think information is subjective or 
personal knowledge. Miller and Steinberg (1975) bring a socio-cultural and psychological dimension to understanding information as knowledge. Various scholars understand information as thinking, cognition, and memory (Burner, 1973; Hunt, 1982; Laszlo, 1969; Luftus \& Luftus, 1976; Masuda, 1980, Pratt, 1977; Schifrin, Castellan, Lindman, \& Pisoni, 1975; Schroder, Driver, \& Streufert, 1967). So diverse is the conception of information that Dizard (1982), Salvaggio (1983), and Schiller (1983) consider information as a technology and Belkin and Robertson (1976) view information as text. Wiener (1961) sees information as uncertainty reduction and his view is supported by Jones (1969), Krippendorff (1977), Lin (1973), Pierce (1961), Rogers and Kincaid (1981), and Rapoport (1966). For Buckley (1967), Masuda (1980), Miller (1965), Ruben (1972, 1984), and Thayer $(1968,1979)$ information is a linkage between living organisms and their environment. Information is also a product of social interaction (Deetz \& Mumby, 1984; Ruben 1975) that has a structure (Laszlo, 1969; Watzlawick, Beavin, \& Jackson, 1967, Weiner, 1961) capable of changing the imagestructure of a recipient (Belkin \& Robertson, 1976). As a stimulus (Bruner, 1973; Jones, 1969) information facilitates learning (Bruner, 1973; MacKay, 1952a, 1952b; Pratt, 1977; Thayer, 1979) and it acts as means for regulation and control in society (Ashby, 1964; Laszlo, 1969; Milsum, 1968; Watzlawick, Bevin, and Jackson, 1967; Young, 1960).

Such diverse understandings have made the conception of information even more complex and often difficult to follow. Ruben (1985) identified several perspectives or conceptions of information that could be found across different disciplines and demonstrated these under a number of dimensions as shown in the following table.

\begin{tabular}{|c|c|}
\hline Dimension & Perspective/Concept \\
\hline $\begin{array}{l}\text { Data (property, } \\
\text { code, pattern) }\end{array}$ & $\begin{array}{l}\text { commodity, code/pattern, } \\
\text { documents, knowledge, } \\
\text { messages, news, physical } \\
\text { forms of property, } \\
\text { processed sensory data, } \\
\text { product, resource, service, } \\
\text { signal, stimuli, structure or } \\
\text { organization, symbols, text }\end{array}$ \\
\hline $\begin{array}{l}\text { Process } \\
\text { (through which } \\
\text { data are } \\
\text { transmitted, } \\
\text { transformed, or } \\
\text { stored) }\end{array}$ & $\begin{array}{l}\text { learning, linkage, process } \\
\text { of being formed, thinking, } \\
\text { cognition, memory }\end{array}$ \\
\hline $\begin{array}{l}\text { Channel or } \\
\text { technology } \\
\text { (means through } \\
\text { which data are } \\
\text { captured, } \\
\text { transmitted, } \\
\text { transformed, } \\
\text { stored, } \\
\text { retrieved) }\end{array}$ & medium, technology \\
\hline $\begin{array}{l}\text { Uses, functions, } \\
\text { or outcomes (of } \\
\text { data } \\
\text { transmission, } \\
\text { transformation, } \\
\text { organization, } \\
\text { management, or } \\
\text { storage) }\end{array}$ & $\begin{array}{l}\text { Consequence of action, } \\
\text { culture formation, decision } \\
\text { making/problem solving, } \\
\text { entropy (decrease in), } \\
\text { meaning, management, } \\
\text { network development, } \\
\text { personality development, } \\
\text { product of social } \\
\text { interaction, reality } \\
\text { construction labeling and } \\
\text { validation, regulation of } \\
\text { control, relational } \\
\text { development, rule and } \\
\text { ritual formulation, structure } \\
\text { or organization, therapy, } \\
\text { thinking, cognition, } \\
\text { memory }\end{array}$ \\
\hline
\end{tabular}

Table 1: Dimension and perspective/concept of information 
Ruben may not have identified every perspective, yet the metrics that he offered is an indication that information has different meanings and usages. Such a diverse understanding of information may be fused into an integrative perspective (Hofkirchner, 1998) that will "bring information theorists together around the concept of information as a theoretical subject." (Doucette, Bichler, Hofkirchner, \& Raffl, 2007, p. 198) The importance of such a perspective is well recognized. However, this essay, which discusses an interpretive understanding of information that can be empirically examined, does not have the scope to elaborate on that. Instead, the article will limit the discussion mainly to the way information has been defined and understood in information science paving a way to support an interpretive or constructive approach to information.

\subsection{Information in Information Science}

Shannon's view of how information is transferred, although it never defined information, developed a ground for theorizing information across different disciplines. Theorizing information within information science also rested on Shannon's information transformation perspective for the many years that the field held a positivistic nature. Over the last few decades, information science has experienced a shift from a predominantly objectivist view of information theory to focus on the phenomena of relevance and interpretation (Capurro \& Hjørland, 2003). This was a shift from the hard science and technical perspectives to social sciences and humanities (Brier, 1992). Various detailed reviews (Cornelius, 2002; Capurro \& Hjørland, 2003; Machlup \& Mansfield, 1983) identify different approaches to information that can be seen primarily as two categories, the mechanistic approach and the cognitive approach, denoting whether information has an objective entity or it is a subjective construct.

The mechanistic approach considers information as a substance residing "in the world." Information systems and the mechanism of information transfer are the focus of this approach. It assumes that information science is an empirical discipline, unconcerned with what information is in an ontological or metaphysical sense (Zund \& Gehl, 1979). The mechanistic approach does not actually give a clear explanation of how something becomes informative. During the first half of the 1990s information scientists began to understand the need to change their approach and focus. Buckland (1991) defined information as a thing that has some reified existence. His view differs from the purely mechanistic in the sense that he defined thing to include tangible and intangible items, knowledge, and process. Agre (1995) advocated a practice-centered understanding of information. He viewed information as an object of certain professional ideologies that can be understood only through the practices by which professionals construct it in their work.

The cognitive approach considers human cognition as necessary for determining what can be called information. This moves the focus from the information system to the user's state of mind. Information science in this phase benefited from ideas from outside the discipline. In this regard Drestke's (1991) information-based knowledge theory and Barwise and Perry's (1983) theory of situational meaning are important (Cupurro \& Hjørland, 2003; Cornelius, 2002); they supplied with the necessary concepts for a cognitive understanding of information. In parallel to the development within cognitive science, where there was a move from symbol manipulation to embedded cognition, a refined, human-centered approach to information emerged: the constructivist approach to information. The constructivist approach focuses on the uniqueness of the individual experience of information; it seeks to understand and theorize how information becomes meaningful to individuals and shared as in a common linguistic, social and cultural context.

Saracevic (1999) viewed information as a continuum of complexity: as signal or message in a narrow sense, as cognitive processing and understanding in a broader sense, and as embedded within a social context. This continuum essentially is congruent with Hjørland's (2007) recent classification of the understanding of information into two basic categories: the 
objective understanding of information and the subjective understanding of information. The objective understanding is observer- and situation-independent. In this sense information has an intrinsic value that has a universal and definite meaning to everyone who has access to it. The narrow sense of information is an example of this objective understanding; the cognitive processing and broad understanding is a subjective or situational understanding of information. According to Hjørland (2007, p. 1449), "What is information for one person in one situation need not be information for another person in another situation. This view of information as a noun is related to becoming informed (informing as a verb). Something is information if it is informative - or, rather, something is information when it is informative". Understanding information as subject- and situation-dependent is an interpretive and constructivist approach that subscribes to phenomenology and aims to understand the individual's role in the process of making information.

Scholars have employed various perspectives within this approach. Cornelius (1996) used symbolic interactionism to unveil how meaning is negotiated in interaction with other meanings. Capurro (2000) preferred a hermeneutic perspective to mark the process of interpretation of the way information is constructed whereas Brier (1995) emphasized a semiotic perspective called cybersemiotics. The theory of autopoiesis represents a further step in this tradition.

Autopoiesis is a radical form of constructivism. Brier (1992), Qvortrup (1993) and Mingers (1995) laid the ground for an autopoietic view of information, but did not offer any direction about how to operationalize such a constructive and interpretive comprehension. In the next two sections, the article briefly discusses the properties of autopoiesis that are relevant for a subjective or interpretive understanding of information. This will be later connected with SpencerBrown's (1973) theory of "laws of form" in order to operationalize such a conception of information that can be used for empirical investigation.

\section{An autopoietic understanding}

"Autopoiesis", combining the Greek words auto (self) and poiesis (creation, production), is a concept involved in the phenomenological understanding of cognition proposed by Maturana (1970); Maturana and Varela (1980) developed this to a systemic explanation of cognition and descriptive phenomenology.

In the autopoietic view cognition is phenomenological. In other words, autopoietic theory describes how living systems address and engage the domain(s) in which they operate. Living systems approach and engage the world in terms of the perturbations in their nervous systems, which are operationally closed, i.e. the transformation occurs within the system's boundary. Living systems constantly reproduce themselves by maintaining their boundaries. The boundary is a distinction that the system makes on its own and the boundary is what makes the system different from another system or the environment. The boundary gives it uniqueness that can be used for manipulations or descriptions in interactions with other observers. An observing subject is a system who observes other systems and the environment.

A system is comprised of organization and structure. The organization is a set of intercomponent relationships, which outlines its form at a given moment and serves as the core "identity" that is maintained by the system. Organization is necessary for a system to become a member of a specific class. The organization's unity is realized through the presence and interplay of components in a given space and time. These comprise the system's structure.

The principle of structural determination is used to understand the system's range of potential structural transformations and the potential perturbations impinging upon the system. Any perturbation may trigger a change of system state, but the particular change is a function of the system's own organization and structure. The basic point is that the behavior of a system is constrained by its constitution, not by the environment.

Structural coupling denotes the way a system interacts, coordinates, and co-evolves with another system or the environment. In 
structural coupling, the participant systems reciprocally serve as sources of compensable perturbation for each other. Here perturbation is understood in the sense of indirect effect or change without having penetrated the boundary of the affected system. This implies that (1) any change in a system is a selfreferential change and therefore the system is closed and (2) an autopoietic system reproduces itself and is thus recursive.

Self-referential observation is the core principle of autopoiesis. An observer, who is a system, observes an environment being governed by the observer's unique structure. This is a second order cybernetic understanding of observation. Observation begins with the observer and ends with the observer. This is how an observer constantly reproduces her/his own structure. Varela (1979) and von Foerster (1981) used the myth of Uroborus, the snake that swallows its own tail, to emphasize the self-referential nature of observation. Like the Uroborus, all observations recursively make the system reenter itself.

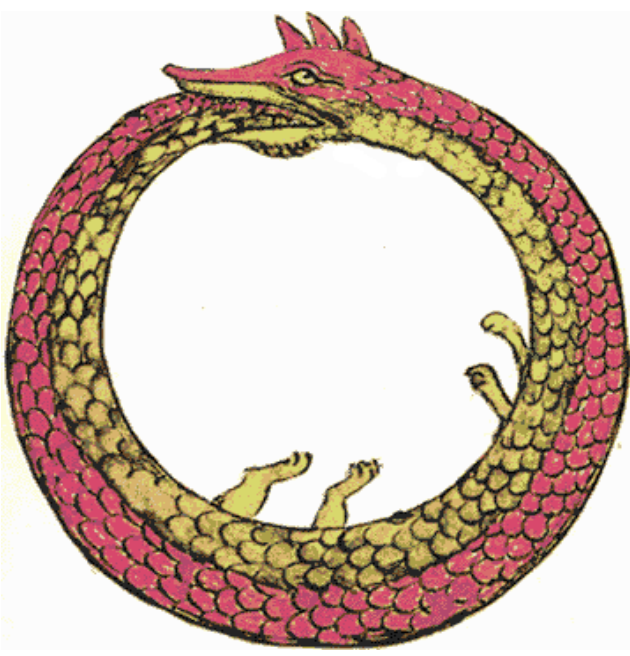

Figure 1: Self-referential observation (Source: 1478 drawing by Theodoros Pelecanos)

A cybernetic approach to examining narratives leads to an individual perspective, where the individual is seen as the starting point for relationships. It further argues that any person should become the author of his or her own story. These stories bring us to perceive the importance of the self and inner experiences. Authoring one's own story or narrative is an inner dialogical experience where one talks to oneself (Bertrando, 2000). In authoring one's own story, one develops texts.

Luhmann $(1986,1995)$ extended Maturana and Varela's autopoietic theory for biological systems to an autopoietic theory for non-living systems like psychic and social systems. A social system allows space for such other systems as the economic, cultural, and religious. Social systems are characterized by their communicative character; they reproduce meaning through a self-referential order and the production of meaning is recursive.

\subsection{Autopoiesis and information}

Perturbation is the point of departure for an autopoietic understanding of information. Qvortrup (1993) considers information as an operational change the external world introduces into an observing system. The individual is a closed system that experiences perturbation through a structural coupling with another system or the environment. Perturbation is a state of change or difference in the interacting system or the environment that triggers a change or difference in the first system. By grounding Bateson's (1972) famous notion of information - difference that makes difference is information - into an autopoietic setting, Brier (1992, pp. 80-81) commented:

"I find that his [Maturana] theory gives a better foundation for Bateson's theory of information through the important point that the autopoietic system does not receive information but only perturbations of its organization. The so called reaction is internal adjustment to preserve the internal organization of the system. It underlines the distinction between the world and its being of differences - potential information if you like - and information processing of the autopoietic system."

Autopoietic information theory denies the existence of any information in the environment and also does not recognize information as thing. Information is a mental state, or change in the individual system-the way the individual relates himself to a 
particular state of the world. It is a phenomenological and constructivist approach.

The cognitive mind relates itself with an external state by interpreting that state selfreferentially. This is done by producing meaning from within those that already exist. In the domain of communicative systems, meanings are the extension and reproduction of the stock of meaning one already has. Therefore, information is also the extension and reproduction of meanings that already exist. The process of reproduction in this regard is understood as evolution. Nothing becomes informative out of the blue: everything that informs is an outcome of a construction. This is a construction process similar to the concept of language games posited by Wittgenstein (1963). A language game views language as a set of tools that we use to construct and assign meaning defined within a particular knowledge system. Similarly, the construction of information is the usage of a set of meanings that a system has in possession. Because the tools, in this case meanings, have boundaries for their operation, the process of assigning meaning is self-referential: one meaning reproduces another by reference to the knowledge system to which the meanings belong. Dretske's (1981) notion of belief as a background for generating knowledge and Gadamer's (1977) concept of pre-understanding have similarity with the way information is self-referential and recursive. An autopoietic system is also analogous to von Uexkull's (1957) concept of Umwelt, which emphasizes an organism's sovereignty and it's self-reference.

The fact that self-referential meaning and therefore the reproduction of information are constrained and shaped by organizational closure implies that a system is intentional in its relating to its environment and to other systems. Intention in this context is similar to Brentano's formulation (Hamlyn, 1984) that intentionality was so obviously inexplicable in physical terms that it proved the existence of a non-material world. Intentionality is comprised of aspiration as well as an individual's need for volition. Intention is not only a private mental phenomenon; it is also expressed in social conventions (Grice, 1989) via signs in speech and other forms.
Recognition of the intent of a system by another one via social conventions brings forth the importance of semiotics in understanding the complexity of structural coupling and its meaningful co-ordination and co-evolution. Semiotics may help unveil this complex structural coupling. Brier (1995), by developing the concept of cybersemiotic - a combination of second order cybernetics, autopoiesis, semiotics, and ethology suggests that we use the triadic and dynamic concept of sign (or semiosis) from C. S. Peirce to give a deeper explanation of what is exchanged, as well as how information is created and has effect on a biological level. Semiotics, both Sussarian and Peircean, discuss sign and symbol; Spencer-Brown's theory of the laws of form, however, analyzes how an observer creates forms by making distinctions and indications. I will use the fundamental concepts and tools of the laws of form to show how an autopoietic understanding of information can be operationalized.

\section{Information as form}

A Platonic perspective understands form as archetypes or abstract representations of the many types and properties of things we see around us. Aristotle was the first to distinguish between from and matter. Spencer-Brown offered a theory, laws of form, denoting how form emerges as an outcome of our observation.

An observer observes by drawing a distinction. To put it another way, what we perceive always follows from an act of making distinctions. In his work Laws of Form, Spencer-Brown (1973) introduced the basic and fundamental human act of making distinction by using an arithmetical notation. Making distinction is fundamental, as this is how something is marked, indicated, and created. Marking an unmarked world is also the way something emerges from the unconscious into conscious, for "consciousness itself is the progressive emergence of a self-reflective, recursive cycle of ever more subtle distinctions" (Robertson, 1999, p. 51).

By making distinctions, which means marking an unknown whole into a known and 
an unknown, form arises and unfolds through different tokens. Engstrom (1999) developed the following sequence to express the process of unfolding:

- Level 0: formless void (wholeness)

- Level 1: distinction

- Level 2: indication (token) regarding the distinction

- Level 3: arrangements of tokens

- Level 4: archetypes (patterns in these arrangements)

- Level 5: infinity, time, feedback, memory

- Level 6: concrete existence (matter, energy)

The emergence of form, by making a distinction that serves as indication, constructs a world by arranging a set of tokens that we make sense of by our observation. The tokens of indications, the markers, are actually signs according to our popular vocabulary. Luhmann (1999) asserts that signs per se do not exist; rather they exist only as forms within the operations of a system that uses them. Signs, in this line of thought, are prerequisites to second-order observation.

Language works as sign when it mediates our orienting behavior. Maturana and Varela (1980) developed the term "orienting behavior" to denote a mode of communication or action through which an organism orients another organism to some other interaction that both the organisms have in common. "Orienting behavior is thus symbolic; its significance lies not in itself, but in what it connotes" (Mingers, 1995, p. 74). Orienting behavior indicates the indication or marks the marking, which means that through orienting behavior humans describe and also describe their descriptions. This in turn forms the basis of language. Mingers (p. 74) further says, "As a result of this process and a concomitant development of the neocortex, organisms have arisen that can make complex and recursive descriptions of descriptions, and thus they become observer." By repeatedly sharing the distinction and description of indication, humans become structurally coupled and that is how one can meaningfully observe another's observations, and thereby understands a description of these observations.
Use of language and the way people punctuate their experience give us an observable corpus to investigate how people observe. This, when recorded, also becomes a resource of the observing people to observe themselves. Sinding-Larsen (1987) calls action or performance recorded on an external device the externalization of knowledge. He attempts to develop an anthropology of information technology where the concept of the externalization of knowledge plays the pivotal role as a historical process. Larson shows how knowledge (i.e., humans themselves) is externalized through a semiotic process. This ongoing process develops tools and artifacts-language, numbers, printing technology, radio, TV, computers-for humans to express themselves over socially shared platforms.

Sinding-Larsen argues that with the process of externalization we externalize the structure and process of knowledge. He elaborates the way language helps us externalize ourselves. For him, "It [language] is a way of living in the world. We try to make our world intelligible through making it readable. In fact, we transform our environment more and more according to our linguistic vision of the world, so most of our living becomes a reading of our own texts" ( $p$. 130). Sinding-Larsen's concept of externalization of knowledge may well be read as analogous to the concept of orienting behavior as both denote how indicated forms are shared.

Forms can be physical or cognitive (Kauffman, 1999); and potential forms in the environment are called objects. According to von Foerster (1981), an object does not exist as an independent entity; something becomes an object only when perceived by an observer. Perceiver and the perceived arise together in the condition of observation. This relationship is called eigenbehavior. The context that we regard as our external world is called eigenform in Foerster's language.

Now that we have spelled out the fundamentals of autopoietic understanding of information and laws of form, let us see how information can be perceived. Our understanding may follow this sequence: 
1. An environment becomes an object when an observer perceives it.

2. Observation is self-referential.

3. An observer makes distinctions of an object.

4. Distinction creates indication.

5. Indication is arranged in tokens.

6. Tokens are form.

7. Form indicates the operational change brought about in an observing system.

8. Operational change is information.

By analyzing tokens of indications it should be possible to perceive how one observes a potentially informative eigenform and assigns meaning to it. In other words, indication forms are the clue to understanding information as constructed by an observer. The following example shows how different observers observe an object differently and thus constructs different information from the same object or no information at all. The author calls it the problem of perceiving September 11.

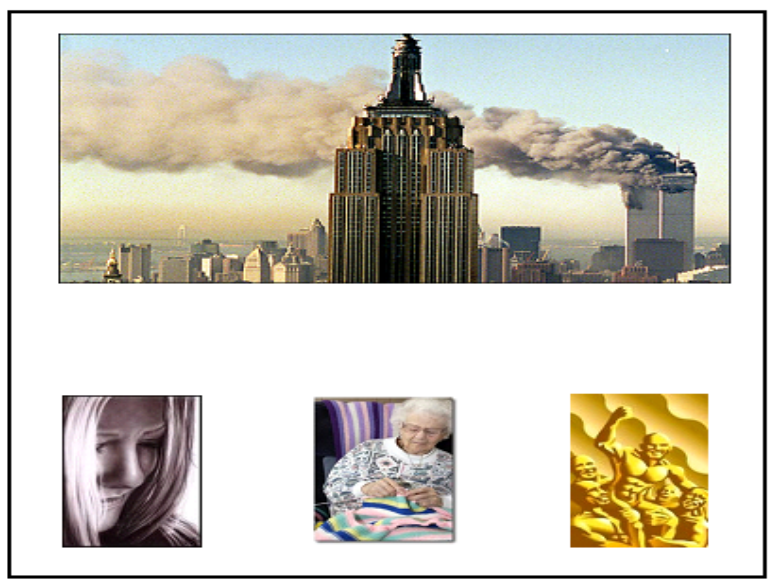

Figure 2: Problem of perceiving September 11

We have four images, of which the top image is an object or environment and the bottom images are indications of three observations and subsequent information. Let us name the object image "Observed" and bottom images from left to right as "Observer 1", "Observer 2" and "Observer 3". "Observed" is an image of destruction of September 11; it is observed by three different observers differently. "Observer 1" is mournful, "Observer 2" is busy in her leisurely sewing work, and "Observer 3" shows an expression of joy and victory. This example demonstrates how different observers may have different eigenbehavior with an object. "Observer 2" does not relate herself with the object and therefore she does not assign any meaning to it or construct any information. "Observer 1" and "Observer 3" make relationships with the "Observed" object but they make distinctions differently - negatively and positively - as is indicated by the token or form created in their expressions. This further reinforces the notion that "Observer 1" and "Observer 3" are perturbed differently by the same object and thus they assign meaning or construct information differently.

\section{Conclusion}

The understanding of information as form -an approach that explores how people (using artifacts or media) self-referentially assign value to environment - is a qualitative exploration of human actions and their interpretations. Therefore, qualitative methods, which investigate human expressions and interpretations, would be appropriate means to conduct research in this area. The act of indication (creating form) is marked in people's expressions (forms) and these expressions or tokens are the empirical clues or data that become the basis for analysis. Analysis of text (linguistic and semiotic) - indication of environment - is expected to unravel the value or meaning people assign to their environment. Content analysis, discourse analysis, and readerresponse analysis are methods that one may employ for such text analysis. These methods are especially valuable because they support exploring and analyzing patterns and forms of human expressions. 


\section{References}

Agre, P. E. (1995). Institutional circuitry: Thinking about forms and uses of information. Information Technology and Libraries 14, 225-230

Artandi, S. (1973). Information concepts and their utility. Journal of the American Society of Information Science, 24(4), 242245.

Ashby, W. R. (1964). An introduction to cybernetics. London: Chapman \& Hall.

Barwise, J., \& Perry, J. (1983). Situations and attitudes. Cambridge, MA: MIT Press.

Bateson, G. (1972). Steps to an ecology of mind. New York: Ballantine Books.

Belkin, N. J., \& Robertson, S. E. (1976). Information science and the phenomenon of information. Journal of the American Society of Information Science, 27(4), 197-204.

Bertrando, P. (2000). Text and context: narrative, postmodernism and cybernetics. Journal of Family Therapy, 22, 83-103.

Boorstin, D. J. (1961). The image: A guide to pseudo-events in America. New York: Harper \& Row.

Boulding, K. (1956). The image. Ann Arbor: University of Michigan Press.

Brier, S. (1992). A critique of the mechanistic concept of information. Cybernetics and Human Knowing, 1(2-3), 71-94.

Brier, S. (1995). Cyber-semiotics: On autopoiesis, code-duality and sign games in bio-semiotics. Cybernetics and Human Knowing 3(1), 3-14.

Bruner, J. S. (1973). Beyond the information given: Studies in the psychology of given. New York: Norton.

Buckland, M. (1991). Information as Thing. Journal of the American Society for Information Science 42 (5), 351-360.

Buckley, W. (1967). The sociology and modern systems theory. Englewood Cliffs, NJ.: Prentice-Hall.

Budd, R. W., \& Ruben, B. D. (Eds.). (1979). Beyond media: New approaches to mass communication. New York: Hayden.

Cannon, D. L., \& Luecke, G. (1980). Understanding communications systems. Dallas: Texas Instrumental Learning Center.

Capurro, R. (2000). Hermeneutics and the phenomenon of information. In C. Mitcham (Ed.), Metaphysics, epistemology, and technology. (pp. 79-85) Elsevier: JAI Press.

Capurro, R., \& Hjørland, B. (2003). The Concept of Information. Annual Review of Information Science and Technology, 37, 353-411.

Cherry, C. (1971). On human communication (2nd ed.). Cambridge, MA: MIT Press.

Cornelius, I. (2002). Theorizing information for information science. Annual Review of Information Science and Technology, 36, 393-425.

Davidson, W. P., Boylan, J. , \& Yu, T. C. (1976). Mass media: Systems and effects. New York: Praeger.

Deetz, S., \& Mumby, D. (1985). Metaphor, information, and power. In B. D. Ruben (Ed.), Information and behavior (Vol. 1, pp. 84-117). New Brunswick, NJ.: Transaction.

Dizard, W. P. (1982). The coming information age: An overview of technology, economics, and politics. New York: Longman.

Doucette, D., \& Bichler, R., \& Hofkirchner, W., \& Raffl, C. (2007). Towards a new science of information. Data Science Journal, 6, 198-205.

Dretske, F. I. (1981). Knowledge and the flow of information. Cambridge, MA: MIT Press.

Engstrom, J. S. (1999). Spencer-Brown's laws of form as a revolutionary unifying notation. Semiotica, 125(1/3), 33-45.

Fisher, B. A. (1978). Perspectives on human communication. New York: Macmillan.

Gadamer, H. (1977). Philosophical hermeneutics (D. E. Linge, Trans.). Berkeley, CA: University of California Press.

Goffman, E. (1974). Frame analysis: An essay on the organization of experience. Cambridge, MA: Harvard University Press.

Grice, P. (1989). Studies in the way of words. London: Harvard University Press.

Hamlyn, D. W. (1984). Metaphysics. Cambridge : Cambridge University Press.

Hjørland, B. (2007). Information: Objective or Subjective/Situational? Journal of the American Society for Information Science and Technology, 58(10), 1448-1456.

Holfkirchner, W. (Ed.). (1998). The quest for a unified theory of information: Proceedings of the Second International Conference on the Foundation of Information Science. Amsterdam: Gordon \& Breach.

Horton, F. W. (1979). Information resources management: Concepts and cases. Cleveland, OH: Association for Systems Management.

Hunt, M. (1982). The universe within: A new science explores the human mind. New York: Simon \& Schuster.

Jones, A. (1969). Stimulus-seeking behavior. In J. Zubek (Ed.), Sensory deprivation: Fifteen years of research. New York: Appleton-Century-Crofts.

Krippendorff, K. (1977). Information systems theory and research: An overview. In B. D. Ruben (Ed.), Communication Yearbook 1. New Brunswick, NJ: International Communication Association.

Lancaster, F. W., \& Gillespie, C. J. (1970). Design and evaluation of information system. Annual Review of Information Science and Technology, 5, 33-46. 
Laszlo, E. (1969). System, structure, and experience. New York: Gordon and Breach.

Lin, N. (1973). The study of human communication. Indianapolis: Bobbs-Merrill.

Lipetz, B. (1970). Information needs and uses. Annual Review of Information Science and Technology, 5, 3-33.

Luftus, G. R., \& Luftus, E. F. (1976). Human memory: The processing of information. Hillsdale, NJ.: Erlbaum.

Luhmann, N. (1986). The autopoiesis of social systems. In F. G. Zouwen (Ed.), Sociocybernetic Paradoxes Observation, control and Evolution of Self-steering System. London: Sage.

Luhmann, N. (1995). Social Systems. Stanford, CA: Stanford University Press.

Luhmann, N. (1999). Sign as form. In D. Baecker (Ed.), Problems of form (pp. 46-63). Stanford, California: Stanford University Press.

Machlup, F. (1962). The production and distribution of knowledge in the United States. Princeton, NJ.: Princeton University Press.

Machlup, F., \& Mansfield, U. (Eds.). (1983). The study of information: Interdisciplinary messages. New York: Wiley.

MacKay, D. M. (1952a). In search of basic symbols. In H. V. Foerster (Ed.), Cybernetics: Transactions of the eighth congress (pp. 58-81). New York: Macy Foundation.

MacKay, D. M. (1952b). The nomenclature information theory. In H. V. Foerster (Ed.), Cybernetics: Transactions of the Eighth Congress (pp. 92-103). New York: Macy Foundation.

Maruyama, M. (1968). Mutual causality in general systems. In J. Milsum (Ed.), Positive feedback: A general systems approach to positive/negative feedback and mutual causality (pp. 80-100). New York: Pergamonon.

Masuda, Y. (1981). The Information society as post-industrial society. Bethesda, MD: World Fortune Society.

Maturana, H. R. (1970). The neurophilology of cognition. In P. Garvin (Ed.), Cognition: A Multiple View (pp. 3-23). New York: Spartan Books.

Maturana, H. R., \& Varela, F. J. (1980). Autopoiesis and cognition: The realizing of the living. Dordech, The Netherland: D. Reidel

McCroskey. (1968). An introduction to rhetorical communication. Englewood Cliffs, NJ.: Prentice-Hall.

McLuhan, M. (1964). Understanding media: The extension of man. New York: McGraw-Hill.

Miller, G. R. (1965). Living systems. Behavioral Science, 10, 193-237.

Miller, G. R., \& Steinberg, M. (1975). Between people: A new analysis of interpersonal communication. Chicago: Science Research Associates.

Milsum, J. H. (1968). Positive feedback: A general systems approach to positive/negative feedback and mutual causality. Oxford, UK: Pergamon Press.

Mingers, J. C. (1995). Self-producing systems implications and applications of autopoiesis. New York: Plenum Press.

Pierce, J. R. (1961). Symbols, signals, and noise. New York: Harper \& Row.

Pratt, A. D. (1977). The information of the image. Libri, 27, 204-220.

Qvortrup, L. (1993). The controversy over the concept of information: An overview and a selected and annotated bibliography. Cybernetics and Human Knowing 1(4), 3-24.

Rapoport, A. (1966). What is information? In A. Smith (Ed.), Communication and culture (pp. 41-55). New York: Holt, Rinehart \& Winston.

Robertson, R. (1999). Some-thing from no-thing: G. Spencer-Brown's laws of form. Cybernetics and Human Knowing, 6(4), 43-55.

Rogers, R. M., \& Kincaid, D. L. (1981). Communication networks: Towards a new paradigm of research. New York: Free Press.

Ruben, B. D. (1972). General system theory: An approach to human communication. In R. W. Budd \& B. D. Ruben (Eds.) Approaches to human communication (pp. 120-144). New York: Spartan.

Ruben, B. D. (1975). Intrapersonal, interpersonal, and mass communication process in individual and multi-person system. In B. D. Ruben \& J.Y. Kim (Eds.), General systems theory and human communication (pp. 164-190). Rochelle Park, NJ: Hayden.

Ruben, B. D. (1984). Communication and human behavior. New York: Macmillan.

Ruben, B. D. (1985). The Coming of the Information Age: Information, Technology and the Study of Behavior. In B. D. Ruben (Ed.), Information and Behavior (Vol. 1, pp. 58-91). New Brunswick, NJ: Transaction Press.

Salvaggio, J. L. (1983). The telecommunications revolution: Are we up to the challenge? In J. L. Salvaggio (Ed.), Telecommunications: Issues and choices for society (pp. 148-153). New York: Longman.

Saracevic, T. (1999). Information Science. Journal of the American Society for Information Science, 50(12), 1052 - 1053.

Schiller, H. I. (1983). Information for what kind of society. In J. L. Salvaggio (Ed.), Telecommunications: Issues and choices for society (pp. 24-33). New York: Longman.

Schroder, H. M., \& Driver, M. J., \& Streufert, S. (1967). Human information processing. New York: Holt, Rinehart \& Winston. Shannon, C. E., \& Weaver, W. (1949). The mathematical theory of communication. Urbana: University of Illinois Press.

Shiffrin, R. M., \& Castellan, N. J., \& Lindman, H. R., \& Pisoni, D. B. (1975). Cognitive theory. Hillsdale, NJ.: Erlbaum. 
Sinding-Larsen, H. (1987). Information technology and the measurement of knowledge. Al \& Society, 1(2), 120-131.

Spencer-Brown, G. (1973). Laws of Form. New York: Crown Publishing Group.

Thayer, L. (1968). Communication and communication systems. Homewood, IL: Irwin.

Thayer, L. (1979). Communication: Sine qua non of the behavioral sciences. In R. Budd \& B. Park (Eds.), Interdisciplinary approaches to human communication (Vol. Hayden, pp. 7-20). Rochelle Park, NJ.: Transaction.

Varela, F. J. (1979). Principles of Biological Autonomy. Amsterdam, North Holland: Elsevier.

Von Foerster, H. (1981). Observing Systems. Seaside, CA: Intersystems.

Von Uexkull, J. (1957). A Stroll through the Worlds of Animals and Men (C. Schiller, Trans.). New York: International University Press.

Whittemore, B. J., \& Yovitz, M. C. (1973). A generalized conceptual development for the analysis and flow of information Journal of the American Society of Information Science, 24, 221-231.

Wiener, N. (1961). Cybernetics: Or control and communication in the animal and the machine (2nd ed.). Cambridge, MA: MIT Press.

Williams, F. (1979). Communication the year 2000. In D. Nimmo (Ed.), Communication Yearbook 3. New Brunswick, NJ.: Transaction/International Communication Association.

Wittgenstein, L. (1963). Philosophical Investigations (G. E. Anscombe, Trans.). Oxford: Blackwell.

Young, J. Z. (1960). Doubt and certainty in science: A biologist's reflection on the brain. New York: Oxford University Press.

\section{About the Author}

Anis Pervez

Anis Pervez is educated in information science (Bloomington), communication (Oslo) and sociology (Dhaka) and has taught different courses in communication, filmmaking, sociology, and development studies in a number of universities in the US and Bangladesh. He also has research and consultancy experiences in different countries. Anis' research interest includes theories of information, development communication, home filmmaking, and film reception. 